\title{
UMA HISTÓRIA DO PIBID CONTADA POR ESTUDANTES DO CURSO DE LICENCIATURA EM MATEMÁTICA
}

\author{
José de Aquino Santos? \\ Larissa Pinca Sarro Gomes²
}

\section{RESUMO}

A formação de professores é uma temática circunscrita em contextos permeados por muitas discussões. Neste artigo, considerando o Programa Institucional de Bolsas de Iniciação à Docência como um espaço significativo para a formação de professores, apresentamos algumas atividades evidenciadas pelos estudantes de iniciação à docência, do curso de Licenciatura em Matemática, que podem trazer contribuições para sua formação. Participaram desta pesquisa, cinco estudantes bolsistas de iniciação à docência de um subprojeto do PIBID, desenvolvido em uma instituição pública de ensino superior, localizada no extremo sul da Bahia, no período de 2011 a 2014. Utilizamos a metodologia da História Oral para a produção de fontes escritas, privilegiando os relatos orais dos estudantes. Também consideramos documentos escritos que nos ajudaram a compreender como aconteceu a articulação entre a instituição de ensino superior e as escolas. Foi possível perceber que as ações realizadas no âmbito desse programa proporcionaram aos estudantes a mobilização e produção de saberes docentes, a partir do estudo de diferentes metodologias para o planejamento de materiais didáticos, dos momentos de reflexão a respeito da trajetória educacional dos estudantes, do trabalho realizado em sala de aula com os alunos da Educação Básica e da divulgação de suas experiências.

Palavras-chave: Formação de professores. Programa Institucional de Bolsas de Iniciação à Docência. História Oral.

\footnotetext{
1 Mestre em Educação Matemática pela Universidade Estadual de Santa Cruz (UESC), Ilhéus/BA. Atualmente, docente das redes Públicas Municipais de Ensino de Eunápolis/BA e Itagimirim/BA. E-mail: akinoprofessor@gmail.com

2 Doutora em Educação pela Faculdade de Educação da Universidade Estadual de Campinas (UNICAMP), Campinas/SP. Atualmente, docente do Programa de Pós-Graduação em Educação Matemática da Universidade Estadual de Santa Cruz (UESC), Ilhéus/BA. E-mail: lpsgomes@vesc.br
} 


\title{
A PIBID HISTORY TOLD BY MATHEMATICS MAJORS
}

\begin{abstract}
Teacher education is a topic situated in contexts permeated with many discussions. In this paper, considering the Institutional Scholarship Program for Teaching Initiation (PIBID) as a meaningful space for teacher education, we present some activities carried out by the teaching initiation students of a Mathematics Licensure course that can contribute to their education. This research had the participation of five Mathematics Licensure majors engaged in a PIBID subproject developed from 2011 to 2014 in a public university in Southern Bahia. We used the Oral History methodology for the production of written sources privileging the students' oral reports. In addition, we considered documents that helped us to understand the interaction between the university and the partner schools. The study revealed that the activities carried out through the PIBID subproject were beneficial to the majors in terms of mobilization and teaching knowledge production as a result of their engagement with different methodologies for the planning of teaching materials, the reflection moments regarding the educational trajectory of the majors, the work done in the classroom with primary and secondary school students and the sharing of their experiences.
\end{abstract}

Keywords: Teacher Education. PIBID. Oral History.

\section{HISTORIA DEL PROGRAMA INSTITUCIONAL DE BECAS DE INICIACIÓN A LA DOCENCIA (PIBID) CONTADA POR ESTUDIANTES DE PREGRADO EN} MATEMÁTICAS

\section{RESUMEN}

La formación de profesores es una temática circunscrita en contextos impregnados por muchas discusiones. En este artículo, consideramos el Programa Institucional de Becas de Iniciación a la Docencia (PIBID) como un espacio significativo para la formación de profesores. Presentamos algunas actividades evidenciadas por los estudiantes de iniciación a la docencia, del curso de Licenciatura en Matemáticas que pueden aportar para su formación. Participaron de esta investigación, cinco estudiantes becarios de iniciación a la docencia de un subproyecto del PIBID desarrollado en una institución pública de enseñanza superior ubicada en el extremo sur de Bahía, en el período de 2011 a 2014. Utilizamos la metodología de la Historia Oral para la producción de fuentes escritas privilegiando los relatos orales de los estudiantes. También consideramos documentos escritos que nos ayudaron a comprender cómo ocurrió la articulación entre la institución de enseñanza superior y las escuelas. Fue posible percibir que las acciones realizadas en el ámbito de este programa proporcionaron a los estudiantes la movilización y producción de saberes docentes a partir del estudio de diferentes metodologías para la planificación de materiales didácticos, de los momentos de reflexión acerca de la trayectoria 
educativa de los estudiantes, del trabajo realizado en clase con los alumnos de Educación Básica y la divulgación de sus experiencias.

Palabras clave: Formación de profesores. Programa Institucional de Becas de Iniciación a la Docencia. Historia oral.

\section{INTRODUÇÃO}

Os debates relacionados à formação de professores são sempre complexos, quando consideramos que esse é um processo imbricado de singularidades pessoais, sociais, históricas, culturais e políticas. Neste artigo, procuramos focar nossas discussões no Programa Institucional de Bolsas de Iniciação à Docência (PIBID), um programa em âmbito federal, com propostas de promover parcerias entre a Coordenação de Aperfeiçoamento de Pessoal de Nível Superior (CAPES), Instituições de Ensino Superior (IES) que ofertam cursos de licenciaturas, e as Instituições de Educação Básica.

Por meio dessas parcerias, surgiu o PIBID em 2007, cuja principal finalidade é desenvolver uma proposta de incentivo e valorização do magistério, buscando interferir no isolamento evidenciado entre teoria e prática, durante a formação inicial de professores (GATTI et al., 2014, p. 5). Como política pública educacional, O PIBID foi institucionalizado e implementado, a partir de editais publicados pela CAPES. Em geral, nos editais eram estabelecidas as diretrizes pelas quais o programa deveria ser desenvolvido.

Assim, nos editais eram divulgadas chamadas públicas para que as IES elaborassem e apresentassem propostas formativas de iniciação à docência. As IES deveriam elaborar um projeto institucional, agregando os seus diferentes cursos de licenciatura e cada um desses cursos deveria desenvolver um Subprojeto que contemplasse suas necessidades específicas.

Nesse sentido, nossas discussões neste artigo, estão voltadas para uma IES localizada no extremo sul da Bahia e no Subprojeto PIBD desenvolvido no curso de Licenciatura em Matemática, no período de 2011 a 2014. A escolha 
do lugar de nossa pesquisa ${ }^{3}$ se deu devido às experiências do primeiro autor ao participar de atividades relacionadas ao PIBID nessa IES e em virtude de sua aproximação com os professores formadores, vinculados ao curso de Licenciatura em Matemática, e estudantes desse curso, bolsistas de iniciação à docência.

Considerando o subprojeto PIBID-Matemática como cenário desta pesquisa, pretendemos compreender, como as atividades formativas, evidenciadas pelos estudantes de iniciação à docência, podem contribuir para a formação do professor de Matemática.

\section{CAMINHOS PERCORRIDOS PARA A ORGANIZAÇÃO E PRODUÇÃO DOS DADOS}

Para responder à inquietude que subsidia o objetivo desta pesquisa, priorizamos a interlocução com os estudantes de iniciação à docência e buscamos por documentos que nos permitissem ampliar nosso entendimento acerca do cenário pesquisado e de seus participantes.

Em uma primeira etapa, realizamos a busca dos documentos oficiais, tendo acesso aos editais do PIBID, o projeto institucional e a proposta do subprojeto PIBID - Matemática, e, possivelmente, compreender as especificidades do PIBID como política pública da Educação. Também tivemos acesso a documentos não oficiais, elaborados pelos bolsistas como as produções científicas, propostas de ensino, materiais didáticos e textos que subsidiaram os estudos e as discussões formativas.

Em uma segunda etapa, consideramos a História Oral como uma metodologia para gerar fontes para esta pesquisa e conduzir a análise dos dados localizados ou produzidos. Ressaltamos que, ao escolher a História Oral como metodologia de pesquisa, estamos cientes de que nosso trabalho não se constitui como uma pesquisa de cunho historiográfico, mas, se propõe a produzir fontes históricas, a partir da oralidade dos depoentes. A esse respeito, Garnica (2005, p. 6) defende que a História Oral tem trazido "[...] contribuições significativas para compreender, de modo geral, o

3 Esta pesquisa foi realizada no âmbito do Programa de Pós-Graduação em Educação Matemática (PPGEM) da Universidade Estadual de Santa Cruz (UESC). 
campo no qual se negociam os significados entre Matemática, ensino e aprendizagem".

A partir do levantamento documental, acessamos a dados que nos permitiram identificar particularidades do subprojeto e todos os participantes envolvidos, no período de interesse desta pesquisa. Para superar o desafio de localizar os estudantes de Matemática, uma vez que o subprojeto foi concluído no início de 2014, recorremos ao critério "contato em rede", em que os primeiros sujeitos localizados indicaram outros. Como alguns exbolsistas ainda estavam cursando a Licenciatura, a partir deles iniciamos o contato com os demais.

Foram encontrados mais de trinta estudantes, no entanto, conseguimos agendar um encontro com cinco deles, que concordaram e tinham disponibilidade para participar de uma entrevista. Os cinco estudantes optaram por adotar nomes fictícios e, por esse motivo, também decidimos pela não identificação da instituição de ensino superior, na qual estavam ou estiveram inseridos. Assim, os depoentes foram identificados neste artigo como Ana, Clara, Júlia, Antônio e Carlos.

Para a entrevista, elaboramos um roteiro com questões norteadoras com o objetivo de constituir, mediante a oralidade dos depoentes, versões a respeito das atividades formativas e de suas experiências ao participarem do subprojeto PIBID-Matemática. Nossa intenção foi constituir narrativas por meio dos relatos orais dos depoentes. Para isso, elaboramos um roteiro que, "[...] embora previamente determinado, é aberto o suficiente para aproveitar as várias experiências relatadas por esses depoentes" (GARNICA, 2012, p. 102). Nesse sentido, as entrevistas realizadas foram semiestruturadas e, para tanto, todos os cinco depoentes receberam o roteiro com antecedência.

Alguns aspectos inerentes à entrevista são substanciais em nossa pesquisa. Para Martins-Salandim (2007), a entrevista é uma técnica também adotada em História Oral, entretanto, ela se diferencia quanto ao uso e abordagem, pois a finalidade é produzir uma fonte ou um documento, não 
simplesmente coletar informações. Além disso, concordamos com Portelli quando afirma que as

[...] entrevistas sempre revelam eventos desconhecidos ou aspectos desconhecidos de eventos conhecidos. [...] Fontes orais contam-nos não apenas o que o povo fez, mas $\circ$ que queria fazer, $\circ$ que acreditava estar fazendo e o que agora pensa que fez (PORTELLI, 1997, p. 7).

Considerando os apontamentos metodológicos do uso da História Oral proposto por Garnica (2012), seguimos um protocolo constituído de duas etapas: a primeira - localizar os depoentes e esclarecer sobre os objetivos de tal ação; entregar o roteiro de entrevista (para facilitar o processo de rememoração); agendar a realização da entrevista em dia, horário e local, considerando o bem-estar do depoente.

A segunda etapa foi constituída das seguintes ações: realizar a entrevista audiogravada; transcrever a entrevista, convertendo-a em registro escrito; textualizar a entrevista, transformando a transcrição em texto ou narrativa; validar o texto/narrativa com o depoente que deve ler a textualização e autorizar o uso ou solicitar ajustes; e o depoente deve assinar um termo que concorda com o uso da textualização ou partes dela para uso em trabalhos científicos.

As entrevistas foram realizadas individualmente, transcritas e textualizadas, preservando ao máximo as singularidades subjetivas expressas pelos depoentes. Mediante o protocolo estabelecido, as narrativas foram disponibilizadas, legitimadas e autorizadas pelos depoentes e somente após a assinatura da carta de cessão de direitos de uso, constituiu-se uma das principais fontes do presente estudo.

Com a leitura desses depoimentos, para este trabalho, fizemos alguns recortes de frases relevantes ditas pelos depoentes que expressaram as suas percepções a respeito das atividades desenvolvidas no âmbito do subprojeto PIBID-Matemática. A partir desses recortes, elaboramos um diálogo com a proposta do Projeto e Subprojeto Institucional PIBID, que aqui resumimos em quatro ações importantes: 
- estabelecer uma relação colaborativa entre os estudantes de licenciatura, os professores formadores e os professores da Educação Básica, a fim de permitir uma reflexão compartilhada sobre problemas da prática de cada um dos envolvidos, com propostas para novos direcionamentos;

- compreender o professor como usuário crítico dos conhecimentos de seu campo de atuação e como sujeito que reflete e produz novos conhecimentos;

- estudar diferentes metodologias para 0 planejamento e desenvolvimento de materiais didáticos para as aulas de Matemática;

- produzir artigos científicos com base na experiência do PIBID para serem apresentados em eventos científicos para socialização das atividades desenvolvidas.

Para conduzir a análise dos dados, também foi importante, a leitura de trabalhos voltados à formação de professores que se preocupam em discutir as transformações dos estudantes, durante 0 processo de preparar professores. Assim, em nossa análise, dialogamos com conceitos e ideias apresentados nos trabalhos de Pimenta (2009), Tardif (2011) e Nóvoa (1992), que serão detalhados nas próximas seções.

\section{OS PROTAGONISTAS DA PESQUISA: estudantes de iniciação à docência}

Para compreendermos as possíveis contribuições do PIBID para a formação de futuros professores de Matemática, tomamos como cerne desse processo, as experiências relatadas pelos estudantes. Nessa perspectiva, realizar entrevistas e constituir fontes proporcionou-nos conhecer uma experiência vivenciada por pessoas que aceitaram rememorá-las, revivê-las e retratá-las, por meio de seus relatos, a seu modo peculiar de narrar e, portanto, de dar sentido e significado à sua verdade, a verdade vivida, experimentada, contada espontaneamente, por isso legítima.

Os cinco depoentes selecionados, em certa medida, caracterizam a dinâmica de inserção e participação dos estudantes da Licenciatura em Matemática no Subprojeto PIBID em diversos momentos de sua execução. Nesse sentido, as versões apresentadas pelos depoentes possibilitam evidenciar diferentes aspectos e fatos significativos inerentes a um processo 
formativo (PIBID) localizado em um espaço e tempo. Conforme Garnica (2012), a oralidade é o ponto de partida para o acesso às memórias dos depoentes.

A estudante Ana, ao ingressar no PIBID em 2011, cursava o sexto semestre de licenciatura e possuía pouca experiência de docência. Durante a entrevista, ela relatou: "não me via sendo professora. [...] mas as ações desenvolvidas no PIBID me deram condições de ser professora de Matemática e com possibilidades de fazer um trabalho diferenciado em sala de aula" (Narrativa de Ana, 2016). Nesse sentido, as ações do subprojeto influenciaram Ana a continuar na licenciatura e, efetivamente, a escolher ser professora de Matemática. Ela participou desde o início até o término do período que delimitamos esta pesquisa.

A depoente Clara ingressou na Licenciatura em Matemática, em busca de uma segunda graduação e estabilidade profissional. Inscreveu-se no PIBID em 2011, quando cursava $07 .^{\circ}$ semestre e tinha experiência de docência. Durante a entrevista, Clara explicitou de maneira incisiva: "Eu fui impactada pelo PIBID. As ações realizadas no projeto PIBID, do qual participei, me influenciaram a perceber que ensinar Matemática supõe aprender a ensinar Matemática" (Narrativa de Clara, 2016). Para Clara, as ações do subprojeto potencializaram e (re)significaram suas percepções sobre docência em Matemática, porque até então ela reproduzia em suas aulas as experiências como estudante.

O ingresso de Júlia no subprojeto ocorreu em 2013, quando ela cursava o terceiro semestre. Em sua narrativa, retratou a relevância do PIBID para o curso de Licenciatura. A estudante afirmou que teve a oportunidade de uma "aproximação com a profissão mais cedo", tendo "contato com a realidade de ser professor" (Narrativa de Júlia, 2016). Para Júlia, vivenciar a docência mais cedo, foi um aspecto preponderante que motivou seu ingresso no subprojeto que estava em andamento.

Antônio ingressou no PIBID em 2011 quando cursava o sétimo semestre e tinha experiência com a docência. Durante sua participação no subprojeto, ele compreendeu que "o bolsista ali inserido percebia que 
lecionar era mais que definição, exemplo e exercícios. A gente sentia a necessidade de aprender para ensinar" (Narrativa de Antônio, 2016). Antônio pontuou aspectos específicos e necessários que foram incorporados na proposta formativa do subprojeto PIBID-Matemática, tais como estudos formativos acerca das diversas metodologias de ensino de Matemática e, a partir delas, planejamentos, elaborações, aplicações e avaliações de propostas de ensino.

Carlos ingressou no PIBID em 2012, quando cursava o segundo semestre da licenciatura. Ele afirmou que decidiu participar do subprojeto porque as discussões complementavam os estudos nas disciplinas "as coisas que faltavam na licenciatura, as discussões sobre ensinar Matemática, sobre o que é ser professor, esclarecimentos sobre formação, a atuação do professor de Matemática" (Narrativa de Carlos, 2016). O depoimento de Carlos denota que ele foi influenciado a participar do subprojeto, pelas possibilidades de aprendizagens para a docência.

\section{O PIBID contado pelos estudantes}

Todas as atividades realizadas no subprojeto PIBID-Matemática, estavam diretamente relacionadas a dois espaços formativos presenciais: a instituição de ensino superior e as escolas da rede pública de Educação Básica, conveniadas ao subprojeto. De algum modo, as singularidades inerentes a essas instituições demarcavam a natureza das atividades didático-pedagógicas e as discussões que envolviam teoria e prática. Ana ressaltou que o subprojeto:

[...] tinha uma proposta que era desenvolvida a partir de etapas: encontros formativos onde eram discutidas as leituras, as propostas de ensino; os chats onde a gente discutia sobre determinados textos; e a escola pública onde nós bolsistas tínhamos que acompanhar as aulas do professor supervisor e desenvolver algumas propostas de ensino. Era tudo bem estruturado, a gente planejava junto com os coordenadores, bolsistas, supervisores e levava as atividades para a sala de aula e a partir disso escrevia trabalhos para eventos (Narrativa de Ana, 2016-grifos nossos). 
Nessa narrativa é possível compreender a estrutura organizacional e metodológica pela qual a proposta formativa do subprojeto PIBIDMatemática era executada. A proposta metodológica que alicerçou as ações do subprojeto tomou como base o trabalho colaborativo para a formação de professores, entendido como "uma oportunidade para que indivíduos aprendam e cresçam juntos" (SUBPROJETO, 2011, p. 4).

Para subsidiar as discussões das ações formativas, os estudantes fizeram a leitura de vários textos ${ }^{4}$ que localizamos ao analisar os documentos disponibilizados no Ambiente Virtual de Aprendizagem (AVA). Entre esses, ressaltamos o livro intitulado Memórias, memoriais: pesquisa e formação docente 5 . A partir desse referencial teórico, os estudantes da licenciatura, no âmbito do subprojeto, vivenciaram oportunidades de refletir aspectos relativos às suas trajetórias estudantis (e perspectivas profissionais), enquanto escreviam sobre tais experiências.

Os registros de experiências representam exercícios de rememorações, que são importantes porque, além de possibilitarem o relato de determinadas experiências vividas na condição de estudante, especialmente aquelas relacionadas ao ensino de Matemática, podem contribuir para problematizar os métodos de ensino que os estudantes de iniciação à docência vivenciaram durante sua trajetória escolar e, por outro lado, pensar na constituição de si mesmo como futuro professor.

Nesse sentido, nos estudos de Pimenta (2009), a autora evidenciou que, ao ingressarem na licenciatura, os estudantes trazem consigo algumas percepções que denotam para eles o que significa ser professor, ou seja, eles têm contato com vários aspectos que caracterizam a profissão docente antes de iniciar o curso de licenciatura. Assim, as experiências das trajetórias pessoal e estudantil contribuem para o desenvolvimento de uma

4 Entre os textos localizados citamos a referência de dois livros utilizados para subsidiar diversas discussões: BORBA, M. de C.; PENTEADO, M.G. Informática e Educação Matemática. 4. ed. Belo Horizonte: Autêntica, 2010; MEYER, J.F.C.A.; CALDEIRA, A.D.; MALHEIROS, A.P.S. Modelagem em Educação Matemática. Belo Horizonte: Autêntica, 2011.

5 PASSEGGI, M. C.; BARBOSA, T. M. N. (Org.). Memórias, memoriais: pesquisa e formação docente. Natal: EDUFERN; São Paulo: Paulus, 2008. p. 176-253. 
concepção ou entendimento pragmático da profissão, entretanto compreender a docência como um processo complexo demanda tempo e exige interações entre futuros professores e outros atores do espaço escolar.

Desse modo, a temporalidade revela-se condição necessária para consolidação e problematização dos saberes docentes, porque aprender a ser professor é inserir-se em um processo de utilização, percepção e reutilização de atitudes, habilidades e conhecimentos. Portanto, ser professor envolve a consciência de agir para superar momentos de dificuldades e incertezas, diante de sujeitos e contextos permeados pela diversidade e singularidades que é uma sala de aula.

Em geral, quando os estudantes escrevem sobre suas trajetórias estudantis, evidenciam aspectos que devem ser problematizados durante sua formação inicial. Ana relembrou que:

\begin{abstract}
Antes de participar do PIBID eu trabalhava com os alunos da forma que eu fui ensinada, com muitos exercícios para o aluno aprender fazer, era aquela coisa da repetição mesmo, tinha que fazer bastantes exercícios. No PIBID foi diferente, tinha que ler, discutir para aprender a ensinar de outras formas. E para mim foi interessante, porque eu fazia também na época os Estágios, e essas experiências se complementavam porque discutiam bastante sobre as realidades da escola e como devíamos fazer para atuar naquele espaço, e tudo a partir de muitas leituras e discussões (Narrativa de Ana, 2016).
\end{abstract}

A estudante revelou como era sua prática docente, denotando que sua percepção de ensino estava arraigada à forma pela qual ela fora escolarizada. Entretanto, ela esclareceu que a partir de sua participação nas ações do PIBID, foi possível construir uma concepção de docência pautada pelo compromisso de aprender para ensinar de outras maneiras. A (re)significação da docência foi percebida por ela, também, enquanto realizava os estágios, reconhecendo a necessidade de considerar as realidades que permeiam o contexto escolar.

Vale ressaltar que no âmbito do PIBID, dadas as diversas experiências vividas pelos estudantes, eles tiveram a possibilidade de perceber suas limitações relacionadas à aquisição ou mobilização de saberes docentes e, consequentemente, suas carências para a docência. Como relatou a 
depoente Júlia, "a visão que eu tinha de ser professor de Matemática estava de acordo com aquilo que eu vivi no ensino básico. Era chegar à sala, dar o conteúdo a partir de definições, exemplos e exercícios, apenas isso" (Narrativa de Júlia, 2016).

As narrativas de Ana e Júlia evidenciaram que, em suas trajetórias estudantis, o ensino de Matemática era concebido com ênfase nos conteúdos e as metodologias de ensino preconizavam o predomínio da repetição de exercícios como meios de promover o aprendizado. A partir de experiências práticas decorrentes da aproximação e vivências em salas de aula, os depoentes denotam compreender a docência em Matemática como articulação de saberes que alicerçam práticas por vezes inéditas.

Nesse sentido, o processo formativo do PIBID, ao articular estudos formativos e práticas docentes de modo imbricado, traduz uma perspectiva de formação discutida por Tardif (2000, p. 14) que considera o sujeito, sua prática e seus saberes como entidades indissociáveis, evidenciando que "saber como viver em uma escola é tão importante quanto saber ensinar em sala de aula". Isso ficou evidente nos relatos dos estudantes acerca dos principais motivos que apontaram como determinantes para participarem do PIBID.

Ana revelou que foi em busca de uma "oportunidade de aprimoramento da prática de ensino no âmbito da escola pública" (Narrativa de Ana, 2016). Em complemento a essa expectativa, Antônio pontuou que sua maior motivação "foi a proposta de estudos na área de tecnologia e resolução de problemas, ambas voltadas para o ensino e aprendizagem de Matemática" (Narrativa de Antônio, 2016).

Parece-nos claro que tanto Ana quanto Antônio, ao ingressarem no subprojeto, reconheciam que estavam em busca de alguns aspectos relevantes para sua formação. Essas motivações, de algum modo, retratam uma percepção por parte dos estudantes da ausência ou necessidade de articular elementos teóricos e práticos à formação e, sobretudo, no contexto prático de sala de aula. A esse respeito, o depoente Antônio, com uma 
experiência de docência na Educação Básica, estabelecida por meio de contratos temporários, explicitou:

[...] com o PIBID era oferecida a oportunidade de formação mais próxima da realidade, discutir os desafios da prática docente [...] a proposta era estudar sobre as metodologias de resolução de problemas e tecnologias e articular essas coisas na prática. Eram justamente as deficiências que os alunos da Licenciatura tinham ao assumir salas de aula porque saber Matemática é diferente de saber ensiná-la (Narrativa de Antônio, 2016 - grifos nossos).

Nessa narrativa, Antônio revelou que o cenário formativo no qual estava inserido proporcionava-lhe discutir os desafios reais da prática docente. Articular metodologias ao processo de ensino de Matemática e perceber que saber conteúdos é diferente de ensiná-los, são aspectos evidenciados por Tardif (2011) como processo de mobilização e produção de saberes docentes.

Nessa direção, o depoente Carlos afirmou que a sua concepção de ensinar Matemática começou a mudar com a participação nas atividades formativas do PIBID, pois "[...] percebia cada vez mais que era necessário ensinar de formas diferentes, mas essas formas diferentes não estão disponíveis o tempo todo, na maioria das vezes o professor precisa ser criativo" (Narrativa de Carlos, 2016).

Em sua narrativa, o estudante avaliou que o professor precisa ser criativo para ensinar Matemática, ou seja, necessita perceber-se como produtor dos saberes necessários ao seu ofício. De acordo com Pimenta (2009), a formação inicial de professor é uma etapa em que a identidade profissional começa a ser construída, portanto, são necessárias ações que permitam aos sujeitos em formação uma aproximação com as atividades da docência.

A participação no PIBID possibilitou que a formação de professores, especialmente a formação inicial, se tornasse um processo articulado à prática docente, em que os estudantes da licenciatura e professores em exercício vislumbrassem, a partir de situações reais e desafiadoras, 
possibilidades de mobilizar teorias e práticas pedagógicas para ensinar Matemática na Educação Básica.

Nessa perspectiva, quanto mais cedo os estudantes problematizarem suas concepções ou percepções de ensino de Matemática, consequentemente mais efetivas serão as produções dos saberes docentes. Conforme Tardif (2011, p. 234), o trabalho do professor "deve ser considerado como um espaço prático específico de produção, de transformação e de saber-fazer específicos ao ofício de professor". Assim, o modo como futuros professores concebem a prática docente influenciará sua prática pedagógica, por isso é imprescindível refletir mediante cenários reais.

Nas reflexões de Carlos (2016), é possível perceber a relação conflituosa, a partir do que estavam discutindo a respeito de um curso de licenciatura, o que ele preconcebia como docência e o que era efetivamente vivido no curso.

Uma questão que ficou martelando foi o modo como as disciplinas pedagógicas eram jogadas para o segundo plano. A postura da maioria dos professores era de extrema valorização à Matemática e isso estava de acordo com o que eu pensava, que o importante era saber os conteúdos (Narrativa de Carlos, 2016).

Nessa narrativa, o depoente Carlos explicitou uma experiência vivida, inerente ao curso de licenciatura em Matemática, que contrasta com suas experiências no PIBID. Esse contraste revela-se importante, na medida em que se torna objeto de discussão evidenciando posicionamentos e atitudes que poderão sedimentar ou transformar determinadas concepções de docência em Matemática.

Por outro lado, a narrativa de Carlos evidenciou aspectos pontuados por Tardif (2011) a respeito da mobilização e produção de saberes docentes, especialmente $\mathrm{O}$ modo como determinados saberes ganham maior relevância em detrimento de outros. A valorização extrema da Matemática em um curso de licenciatura reforça maior legitimação aos saberes disciplinares (que, em geral, a produção é exterior ao professor e sua prática) em detrimento dos saberes curriculares ou dos experienciais. 
Embora reconheça a importância e a necessidade da articulação de distintos saberes na docência, Pimenta (2009) ressalta que os saberes da experiência, aqueles provenientes das distintas interações sociais, adquiridos em diversos contextos, encontram significados ou ressignificam a prática ou a formação para a prática docente.

Essa perspectiva de formação, em certa medida, era contemplada na dinâmica formativa do subprojeto. Por ser constituído por etapas presenciais e virtuais, subsidiadas por leituras, discussões, planejamentos e avaliações, o subprojeto PIBID revelou-se propício para a formação docente. Conforme explicitou Carlos (2016), "era a partir dessas etapas que a gente começava a ver a prática docente, principalmente as coisas que antecedem o ato de ensinar".

Nessa perspectiva, a depoente Clara evidencia que o PIBID contribuiu, tanto para a constituição da identidade profissional, quanto para a valorização do magistério. Clara revelou que:

O PIBID promoveu encontros com alternativas de ensino e introduziu a ideia de pesquisadora. Eu fui impactada pelo PIBID, eu quero saber mais para ser uma professora melhor e reconhecida como a professora de Matemática que sabe ensinar Matemática (Narrativa de Clara, 2016).

A narrativa de Clara demonstra que no subprojeto PIBID a dimensão de pesquisa foi introduzida na formação como uma característica de profissionalização, e esse aspecto contribui para a constituição progressiva da identidade e desenvolvimento profissional, conforme ressaltou Nóvoa (1992). Além disso, fica evidente a valorização do Magistério, considerando que a depoente reafirma o objetivo de querer saber mais para ser reconhecida como professora que sabe ensinar Matemática.

Vale salientar que a relação que o professor tem com os saberes docentes, segundo Tardif (2011), é imprescindível para sua formação, atuação e desenvolvimento profissional, porque a valorização da profissão, a autonomia e, sobretudo, a criatividade do sujeito para atuar na docência dependem muito de como ele se percebe nesse processo de ensino. Por 
isso, é necessário que professores e futuros professores se reconheçam como produtores de saberes docentes para que a Matemática escolar tenha um caráter social.

Para Tardif (2011) e Pimenta (2009), os saberes docentes são oriundos de diversos contextos e situações, que, de algum modo, estão vinculados à docência, seja de forma retrospectiva (no exercício do trabalho) ou prospectivamente (na formação para o trabalho docente), e, nessas condições, no cotidiano escolar, diferentes saberes docentes são elaborados e reelaborados. A narrativa de Carlos evidenciou essa dimensão característica dos saberes docentes, ao reconhecer:

Outra coisa bem legal, aprendemos a fazer videoaulas. Assim, os alunos visualizavam, manipulavam, perguntavam e aprendiam. Algumas atividades, eles mesmos realizavam usando o computador e os softwares gratuitos. Eles construíam, por exemplo, figuras planas e observavam as características delas, e quando manipulavam determinados elementos das figuras viam o que acontecia e com isso aprendiam com significado (Narrativa de Carlos, 2016).

A produção de videoaulas, para os estudantes, passou a ter outro significado, deixando de ser um mero recurso tecnológico e tornando-se um recurso pedagógico, ou seja, eles perceberam que a inserção de tais recursos no processo de ensino de Matemática possibilita aprender essa disciplina com dinamismo e autonomia. Ademais, os estudantes da licenciatura perceberam-se como sujeitos ativos nesse processo, isto é, produtores de alternativas que potencializaram o aprendizado de outros sujeitos.

Cabe destacar que a produção de saberes docentes não precisa ser algo inédito, mas é necessário que os estudantes de licenciatura tenham oportunidades de (re)significação de saberes, adaptações e inserções de diferentes recursos para o ensino de Matemática. Essas oportunidades surgiram nas atividades realizadas no âmbito do PIBID, em particular, nos encontros formativos. Como nos revelou Júlia, durante esses encontros, os estudantes "planejavam e discutiam possibilidades de novas propostas de 
ensino [...] porque a gente vai mesmo para o contato com a realidade de ser professora" (Narrativa de Júlia, 2016).

A estudante Júlia relembrou que:

\begin{abstract}
A proposta do subprojeto era inserir as tecnologias nas atividades de sala de aula [...], a partir do plano de curso que o professor supervisor tinha para ser desenvolvido durante o ano letivo, a gente procurava elaborar atividades e aplicava na sala de aula. [...] a gente discutia muito acerca dos entraves no processo de ensino e aprendizagem de Matemática, e nessas discussões a gente buscava criar meios de atender às necessidades dos alunos (Narrativa de Júlia, 2016).
\end{abstract}

As interações com o professor supervisor eram fundamentais para a elaboração de atividades que seriam aplicadas nas aulas de Matemática. Esse processo era antecedido por observações das aulas e acesso ao planejamento anual e plano de aulas referentes à disciplina de Matemática, conforme pudemos apreender na narrativa do depoente Carlos, que ressaltou:

Para organizar as propostas de ensino, a gente considerava, principalmente, as dificuldades dos alunos. Como a gente participava das aulas do professor supervisor, percebia essas dificuldades. Além do mais, nós tínhamos acesso ao planejamento anual dele, aos planos semanais e planos de aula e considerávamos também as avaliações aplicadas (Narrativa de Carlos, 2016).

Essa narrativa indica que os estudantes tinham acesso a documentos que oportunizavam a apropriação e a mobilização de saberes curriculares, que, conforme Tardif (2011)revelam aspectos relativos aos objetivos, avaliação, metodologia, entre outros elementos normativos, que antecedem e se imbricam na docência. Entre esses elementos destacam-se as avaliações aplicadas que foram tomadas como instrumentos, a partir dos quais as dificuldades dos alunos eram diagnosticadas e as atividades e estratégias de intervenção eram elaboradas.

A elaboração e a aplicação de atividades didáticas sempre representaram desafios aos estudantes de iniciação à docência e, considerando a conjuntura, podemos destacar: a diversidade de conteúdos 
matemáticos; as especificidades de cada conteúdo; o modo como os estudantes concebem o ensino de tais conteúdos; o contexto escolar, as subjetividades/heterogeneidades pertinentes aos alunos etc. Esse aspecto foi relatado pelos depoentes ao mencionarem algumas atividades realizadas:

O exemplo mais marcante, principalmente porque as dificuldades possibilitaram mais aprendizagem, foi a proposta de elaborarmos um material didático. Primeiro porque devíamos abordar vários conteúdos das séries/anos que o supervisor ministrava aulas. Além disso, o ensino desses conteúdos deveria ser articulado com as metodologias estudadas e amplamente discutidas, como Resolução de Problemas e Tecnologias (Narrativa de Carlos, 2016).

O material didático foi uma proposta executada pelos estudantes no âmbito do subprojeto. Nesse material, os estudantes deveriam propor alternativas de ensino de conteúdos matemáticos, em consonância com o planejamento anual do professor supervisor, articulando as metodologias estudadas. A depoente Júlia esclareceu:

$\mathrm{Na}$ proposta do material didático, a gente iniciava o conteúdo sempre com uma contextualização, seja ela histórica, ou a partir de um problema, e logo depois vinha inserindo os recursos tecnológicos, na maioria das vezes era o GEOGEBRA, e só a partir disso é que era apresentado o caráter formal do conteúdo (Narrativa de Júlia, 2016).

A produção de materiais didáticos demandou dos estudantes, no âmbito do subprojeto, mobilização e produção de saberes docentes, uma vez que deveriam apresentar um conteúdo que tivesse um encadeamento lógico nas atividades propostas e considerassem articulações entre metodologias e recursos didáticos. Outro aspecto evidenciado na narrativa de Júlia é considerado imprescindível à formação inicial de professores, conforme Pimenta (2009), diz respeito à pesquisa como fundamento e prática na formação docente.

Além da pesquisa, para apresentar o conteúdo, considerando aspectos históricos ou partindo de um problema que motivasse os alunos a resolvê-lo, o professor e, no caso específico, o bolsista de iniciação, devem dominar o conteúdo matemático a ser trabalhado em sala de aula. Trata-se 
de uma condição necessária para auxiliá-los nessas escolhas, o que foi enfatizado por Antônio:

[...] a gente já ia organizando as oficinas com aquele conteúdo, de forma dinâmica e alternativa. Para isso, eram usados recursos manipuláveis, alguns softwares (principalmente, o GeoGebra). [...] Mas, antes de tudo, a gente teve que aprender como ensinar o conteúdo e como elaborar as oficinas e outras atividades de intervenção de ensino de Matemática (Narrativa de Antônio, 2016 grifos nossos).

A relação indissociável entre aprender o conteúdo e aprender como ensiná-lo, revela uma concepção de formação, em que ensinar torna-se uma ação pautada pela responsabilidade e compromisso profissional com a docência. Conforme ressaltou Tardif (2011, p. 20), "[...] ensinar supõe aprender a ensinar, ou seja, aprender a dominar progressivamente os saberes necessários à realização do trabalho docente".

Os aspectos formativos no âmbito do subprojeto, além de contemplarem a pesquisa para fundamentar a relação teoria e prática com finalidade para a docência, tangenciavam a perspectiva de formação com ênfase nos desafios de divulgação de suas experiências em outros espaços acadêmicos mediante produções científicas. A esse respeito, Ana revelou outra característica do PIBID a possibilidade de:

[...] participar de eventos, de pesquisar, de escrever trabalhos para apresentar, porque até então a gente só participava de eventos como ouvintes e eu queria essas oportunidades (Narrativas de Ana, 2016).

Nessa narrativa, Ana demonstrou ter consciência da necessidade de complementar sua formação inicial, mediante produções de trabalhos acadêmicos, participação em eventos externos à IES da qual era estudante e, sobretudo, superação da condição de sujeito ouvinte. Essa dimensão formativa demarca, além de um reconhecimento do próprio sujeito quanto ao seu potencial de autonomia, criticidade e criatividade, um desenvolvimento e vivência prática da pesquisa como elemento fundamental da formação docente. 
A produção desses trabalhos científicos consolida resultados de um trabalho coletivo, visto que eram produções oriundas de estudos, discussões, avaliações e aplicações práticas. A coletividade inerente a essas produções, oportunizavam aos estudantes a articulação de culturas intelectuais distintas, os discursos, experiências e vivências de sujeitos da universidade (professores e licenciandos) e sujeitos da Educação Básica (professores e alunos). Assim, são articulados, segundo Tardif (2011), saberes provenientes da formação profissional, saberes curriculares, saberes disciplinares e saberes experienciais.

Outro aspecto importante decorre da submissão e consequentes apresentações dessas produções, que passam por apreciações distintas, debates, sugestões, criticas e, por conseguinte, comparações e reformulações. Nesse sentido, os estudantes no âmbito do subprojeto têm novas oportunidades de aprendizagens da docência, mediante desafios tanto da produção quanto da apresentação. Esses dois aspectos distintos e complementares contribuem para a formação docente preconizada por Tardif (2011), que compreende o professor como produtor de saberes docentes.

A inserção da pesquisa, como elemento potencializador da formação docente, no subprojeto foi imprescindível, como revelou Antônio ao reconhecer:

[...] aprendemos a escrever trabalhos científicos, artigos, relatos de experiência, oficinas, minicursos, projetos etc., porque muito do que foi lido, discutido e aplicado foi convertido em produções científicas para serem divulgadas, apresentadas em eventos (Narrativa de Antônio, 2016).

A narrativa de Antônio esclareceu que a escrita de trabalhos científicos foi resultado de um processo amplo, articulado e consequentemente cíclico, pois muito do que foi vivenciado e experimentado foi registrado e divulgado. Os diferentes trabalhos científicos produzidos sedimentaram, sobretudo, a aprendizagem da docência como um processo de interações humanas. 
Vale salientar que a finalidade do subprojeto não era, propriamente, exigir dos estudantes a escrita de produções científicas. Entretanto, essa dimensão fora contemplada, a partir da própria dinâmica formativa, organizada a partir de leituras, discussões e produções de atividades para o ensino de Matemática. Consequentemente, tais atividades contribuíram para que os próprios estudantes se sentissem encorajados para a escrita de suas experiências.

A articulação dessas distintas experiências formativas desenvolvidas no âmbito do subprojeto evidenciou um processo de reflexão e mudanças de concepções por parte dos estudantes. A esse respeito, Antônio comparou duas experiências diferentes:

Entre o PIBID e os Estágios tem muita diferença. O PIBID proporciona mais oportunidades, mais bagagens, conhecimentos diferenciados. A gente tem tempo para aprender, e no Estágio a coisa é mais engessada. A gente chega com tempo corrido para aplicar coisas que aprendemos. No PIBID a gente tem tempo para ler mais, discutir, aplicar e depois voltar e refletir sobre o que foi feito. Eu mesmo percebo que hoje eu faria tudo diferente em minha prática. Até meu modo de estudar, de me organizar nas disciplinas e no Estágio. Se eu já tivesse essa bagagem do PIBID eu faria tudo diferente [...] (Narrativa de Antônio, 2016).

Apesar de as atividades do PIBID e de os Estágios Supervisionados serem desenvolvidos durante a formação, no curso de licenciatura la primeira de caráter complementar e o segundo de caráter obrigatório), Antônio ressaltou a diferença entre esses dois processos formativos. Em sua experiência, O PIBID possibilitou uma aprendizagem mais autônoma e isso pode ser percebido na própria estrutura do programa, o que proporcionou mais tempo para leituras, discussões, planejamento de atividades e reflexões a respeito do trabalho realizado em sala de aula.

Esse movimento, contado pelos estudantes, revelou que o subprojeto PIBID foi desenvolvido em uma perspectiva de formação colaborativa, fato que possibilitou a reflexão como prática imprescindível à docência. Ao executarem as etapas formativas, os estudantes percebiam as nuances inerentes à escola e, nesse entremeio, foram construindo condições para 
atuarem nesse espaço profissional com saberes e competências para superar os desafios da docência, entendida como processo de interação entre sujeitos.

\section{ARREMATES E PERSPECTIVAS: algumas considerações}

Considerando os dados localizados e produzidos, oriundos de documentos oficiais e das narrativas dos depoentes, e nossas interlocuções entre essas fontes e os aportes teóricos adotados, foi possível compreender que as atividades formativas, desenvolvidas no âmbito do subprojeto PIBID, contribuíram para a formação do professor de Matemática.

Os estudantes mobilizaram e produziram saberes docentes articulados nas diversas etapas do subprojeto relacionadas aos encontros formativos presenciais e virtuais, nas atividades de iniciação à aprendizagem da docência na Educação Básica, nos planejamentos e produções de atividades e nas escritas de trabalhos e participações em eventos científicos.

Os saberes docentes caracterizados por Tardif (2011) como da formação profissional, da experiência, disciplinares e curriculares foram mobilizados e produzidos, na medida em que os estudantes discutiam, planejavam e elaboravam propostas de ensino subsidiadas pelas metodologias de ensino de Matemática e as interações com outros sujeitos. Esses aspectos contribuíram para os estudantes compreenderem as relações existentes entre os saberes docentes e as formas como esses podem ser retraduzidos na prática docente.

A partir de suas narrativas, além de compreenderem como estava organizado o subprojeto, os depoentes relataram a importância de discussões a respeito das concepções de formação, de docência, de Matemática e de Educação. Eles relataram, cada um a sua maneira, como concebiam a docência em Matemática e constituíram novas concepções não pelo discurso, mas pelas experiências formativas que se permitiram viver. Do mesmo modo, (re)significaram as concepções de Matemática e de Educação e, consequentemente, perceberam que ensinar Matemática é bem mais do que ensinar conteúdos. 
Inseridos no subprojeto PIBID-Matemática, perceberam a importância da participação em um grupo com experiências diversas, do qual participaram professores universitários, professores da Educação Básica e estudantes de licenciatura, cada um trazendo importantes contribuições que ajudaram no desenvolvimento individual e do grupo.

As diferentes experiências formativas, nas quais os estudantes de Matemática estiveram envolvidos, possibilitaram-Ihes perceber a relação entre o professor e os saberes docentes como um processo interno e social, porque são sempre passivos de ser (re)significados e atualizados mediante situações reais de vivências e aproximações com a docência. Nesse sentido, - PIBID consolida a materialização de possibilidades de articulação entre Instituição de Ensino Superior e Instituições de Educação Básica na formação de professor.

Assim, podemos destacar que o PIBID, como política pública educacional, pode potencializar a formação docente, promover a valorização do Magistério e formar professores conscientes da necessidade e possibilidade de serem críticos, criativos e produtores de saberes necessários para o exercício da docência. Diante do exposto, almejamos que este trabalho possa trazer contribuições para a formação de professores de Matemática e possibilite a realização de pesquisas em outros contextos formativos.

Considerando que nossas compreensões se deram a partir de um contexto constituído por pessoas singulares, ideias, ações e concepções de mundo particulares, reconhecemos outras necessidades e possibilidades de fomentar pesquisas inerentes à formação de professores de Matemática, ao PIBID como política pública educacional e aos saberes docentes.

Entre as possibilidades inerentes ao nosso cenário de pesquisa, as seguintes indagações são pertinentes para pesquisas futuras: Como o subprojeto PIBID-MATEMÁTICA contribuiu na formação dos professores supervisores? Como as ações formativas do subprojeto PIBID-MATEMÁtICA influenciaram as propostas de formação no curso de Licenciatura em Matemática? 
Acreditamos que pesquisas nesse sentido podem contribuir para compreender as nuances da formação do professor de Matemática e constituir novas propostas subsidiadas pelas relações: teorias e práticas pedagógicas; Instituições de Ensino Superior e escolas da Educação Básica; professores e estudantes das licenciaturas; professores, estudantes e alunos da Educação Básica; tecnologias disponíveis; e as demandas de ensino e aprendizagem. Essas propostas têm como cerne o professor de Matemática, que ocupa uma posição estratégica que perpassa pela percepção de si como pessoa criativa e produtora dos saberes, habilidades, competências e atitudes.

\section{REFERÊNCIAS}

BRASIL. Edital Capes/DEB n. 02/2009. Programa Institucional de Bolsas de Iniciação à Docência. Brasília, 2009.

BRASIL. Edital n. 001/2011/Capes. Programa Institucional de Bolsa de Iniciação à Docência - PIBID. Brasília, 2011.

BRASIL. Fundação Coordenação de Aperfeiçoamento de Pessoal de Nível Superior. Edital PIBID n. 02/2009, de 25 de setembro de 2009. Brasília: CAPES/DEB, 2009

GARNICA, A. V. M. A história oral como recurso para a pesquisa em Educação Matemática: um estudo do caso brasileiro. Comunicação apresentada no V Congresso Iberoamericano de Educação Matemática, Porto, jul. 2005. Disponível em: <www.jurandirsantos.com.br>.

GARNICA, A. V. M. História oral e educação matemática. In: BORBA, M. C.; ARAÚJO, J. L. (Org.) Pesquisa qualitativa em educação matemática. 4. ed. Belo Horizonte: Autêntica, 2012. p. 87-109.

GATTI et al. Políticas docentes no Brasil: um estado da arte. Brasília: Unesco, 2011.

GATTI et al. Um estudo avaliativo do Programa Institucional de bolsa de Iniciação à Docência (PIBID). São Paulo: FCC/SEP, 2014. Disponível em: <www.fcc.org.br/biblioteca/publicacoes/textos>.

MARTINS-SALANDIM, M. E. A interiorização dos cursos de Matemática no Estado de São Paulo: um exame da década de 1960. 2012. 379 f. Tese (Doutorado) - UNESP, Rio Claro, 2012.

MEIHY, J. C. S. B. Manual de história oral. 3. ed. São Paulo: Loyola, 2002. 
NÓVOA, A. (Org.). Os professores e sua formação. Lisboa: Dom Quixote, 1992.

PIMENTA, S. G. Formação de professores: identidade e saberes de docência. In: PIMENTA, S. G. Saberes pedagógicos e atividade docente. 7. ed. São Paulo: Cortez, 2009.

PORTELLI, A. O que faz a história oral diferente. Projeto História, Revista do Programa de Estudos Pós-Graduados em História e do Departamento de História da PUC/SP, São Paulo, n. 14, p. 25-39, fev. 1997.

PROJETO INSTITUCIONAL PIBID-Matemática. Salvador, BA, 2011. (Material não publicado).

Recebido em: 29 de março de 2018.

Aprovado em: 31 de agosto de 2018. 